\title{
TOWARD AN IMPROVED PORTFOLIO VARIANCE MEASURE OF REGIONAL ECONOMIC STABILITY
}

\author{
Paul B. Siegel, Jeffrey Alwang, Thomas G. Johnson*
}

\begin{abstract}
The portfolio variance has gained popularity as a tool to evaluate altemative strategies that promote regional coonomic stability. As it is commonly applied, however, the portfolio variance has several problems that limit its appropriateness for regional economic analysis. There are several implicit sesumptions about the relationship between structural change and atability, and about the emphasis on aggregate region-wide stability that should be recognized when using the portfolio variance approach to predict the impact of alternative diversification strategies. These assumptions and their implications are discussed, and an improved portfolio variance measure of regional economic stability is presented.
\end{abstract}

\section{INTRODUCTION}

The portfolio variance has gained popularity as a tool to evaluate altemative strategies that promote regional economic stability. Despite its growing popularity, there are some problems in using the portfolio variance approach to predict the impact of altemative diversification strategies on a region's economic stability.

Applications of the portfolio variance to regional economic analysis are hampered by data and conceptual problems. Data problems have been shown to limit the effectiveness of these models for small regions (Schoening and Sweeney 1989). There are also a number of conceptual problems associated with the use of portfolio-based models for regional economic analysis, since these models were originally formulated for the analysis of financial asset markets (Sherwood-Call 1990; Schoening and Sweeney 1992).

In addition to data and conceptual problems pointed out by other authors, there are two fundamental problems with the portfolio variance approach as it is commonly applied to analyses of regional economic stability. First, most applications incorrectly treat variations in outcomes as if they did not depend on the composition of the remainder of the portfolio (i.e., the structure of the economy). In fact, variations in outcomes, such as sector-specific employment or income, depend on the overall composition of the regional portfolio. Second, there are conceptual problems related to the emphasis on aggregate region-wide economic

\footnotetext{
*Assistant Professor, Department of Agricultural Economics and Rural Sociology, University of Temnessee, Knoxville, and Assistant Professor and Professor, Department of Agricultural Economics, Virginia Tech, Blacksburg, respectively.
} 
stability as measured by the portfolio variance. There are questionable assumptions about the stability faced by individuals or groups within the regional economy and the intergroup mobility or adjustment of labor and capital in response to fluctuating economic conditions. These conceptual problems severely limit the use of the portfolio variance approach for regional economic analyses.

The purpose of this paper is to discuss the implications of these two problems and to suggest means of avoiding or minimizing them. In order to do so, the portfolio variance approach, as it is commonly applied to studies of regional economic diversification, is presented. The two problems with the portfolio variance approach are outlined next. Particular attention is paid to the assumptions needed to justify ignoring the impacts of these problems. The implications of these limitations for policymaking are discussed. Some guidelines for the correct use of portfolio analysis for regional economic stability are presented, including an improved portfolio variance measure of regional economic stability.

\section{THE PORTFOLIO VARIANCE AND REGIONAL ECONOMIC STABILITY}

There have been numerous attempts over the past 60 years to construct an ideal measure of a region's economic diversity. Because of the hypothesized positive relationship between economic diversity and stability, it was believed that such a measure of diversity could be used to guide industrial targeting and recruitment strategies toward an economic structure with greater stability (Kort 1991). Conroy $(1974 ; 1975)$ suggested that the portfolio variance could be used as a measure of region-wide economic diversity and stability.

In addition to the portfolio variance, there are several other ways to define a region's economic diversity. Depending on the definition, different measures (or indices) of economic diversity arise such as the ogive index, national averages index, percent durable goods index, entropy index, etc. (Kort 1991; Wundt 1992). If the absence of instability is used to define a diversified economy, then the portfolio variance is a particularly well-suited index of economic diversity at a given point in time.

The portfolio variance measure is a share-weighted, region-wide aggregation of group-specific and intergroup fluctuations. The portfolio variance uses information about the stability of outcomes (e.g., employment, income) from individual subgroups and the interdependence of fluctuations between the component groups of the region's "portfolio" (or economic structure) to construct an aggregate measure of economic stability. Simply, "the portfolio variance .... 
correctly calculated, is exactly the same as a region's total variance which is a frequently-used measure of economic instability" (Sherwood-Call 1990, 20).

A region's portfolio variance, PVAR[Z], can be expressed as:

$$
\operatorname{PVAR}[Z]=\sum_{i=1}^{n} \sum_{j=1}^{n} W_{i} W_{j} \operatorname{VAR}\left[Z_{i j}\right],
$$

or, altematively, as:

$$
\operatorname{PVAR}[Z]=\sum_{i=1}^{n} W_{i}^{2} \operatorname{VAR}\left[Z_{i}\right]+\sum_{i=1}^{n} \sum_{j=1, j \neq i}^{n} w_{i} W_{j} \operatorname{COV}\left[Z_{i}, Z_{j}\right],
$$

where the components $W_{i}$ and $W_{j}$ are the shares of economic activity for the ith and $j$ th groups, $Z_{i}$ and $Z_{j}$ are returns (usually employment or income) from the ith and $j$ th groups, $\operatorname{VAR}\left[Z_{i}\right]$ is the variance for the ith group, and $\operatorname{COV}\left[Z_{i}, Z_{j}\right]$ is the covariance in outcomes between the ith and jth groups (based on deviations between actual and expected outcomes).

PVAR[Z] is generally constructed by using one-, two-, or three-digit SIC codes for the $i$ group outcomes $\left(Z_{i}\right.$ and $\left.Z_{j}\right)$, with each variance and covariance term normalized by the appropriate group mean or trend. The portfolio variance, PVAR[Z] in Equation (2), can be decomposed into the components of total aggregate instability: (1) variance (i.e., instability resulting from individual group fluctuations) and (2) covariance (i.e., instability resulting from intergroup fluctuations) terms.

In most studies that apply the portfolio variance approach, economic diversification is defined as a structural change that reduces region-wide instability. Such a reduction is achieved by varying the relative shares of different sectors (e.g., by increasing the shares of sectors that lower aggregate region-wide instability). Thus, in the sense that regional economic diversity corresponds to increased stability of economic outcomes, PVAR[Z] as described above can in principle be used to rank the outcomes of alternative economic diversification strategies.

Consequently, a recent article in The Review of Regional Studies claims that: The one measure that may provide a basis for a diversification strategy for regions is the portfolio variance (Wundt 1992, 66). because,

[it] provides an accurate measure of overall instability, information on the cyclical characteristics of individual industries, and a method to identify stability-promoting industries (Wundt 1992, 69).

Despite its usefulness, there are some conceptual problems that must be recognized when using the portfolio variance to predict the impact of altemative 
diversification strategies. This paper details two problems with applying the portfolio variance that have not been dealt with previously in the literature: (1) assumptions about the relationship between changes in economic structure and economic stability, and (2) assumptions related to the focus on aggregate regionwide stability. These conceptual problems and their implications for regional economic analyses are described and discussed below.

\section{RELATIONSHIP BETWEEN CHANGES IN ECONOMIC STRUCTURE AND ECONOMIC STABILITY}

There is a major conceptual problem related to the construction of the portfolio variance when it is applied to predict the impacts of changing a region's economic structure. Sector variances and covariances are assumed not to depend on the other sectors included in the portfolio. Although the covariance terms capture the relationship between individual sectors and how they interact to affect aggregate region-wide economic stability, these covariances do not capture the fact that variances and covariances of individual sectors themselves change as economic structure changes. Thus, the endogeneity of variances and covariances is not considered.

The assumption that the variances of individual assets do not depend on other assets is plausible when modelling financial asset markets because the variability in returns from, for example, stocks within a given individual's portfolio, does not depend on the other assets in that individual's portfolio such as bonds. Variations in returns are exogenous to the individual economic agents, and total aggregate portfolio variability depends only on the asset shares $\left(W_{i}, W_{j}\right)$ and on the exogenous variances and covariances. In the case of a regional economy, however, the variances in sectoral employment and income themselves depend on the other sectors included in the regional portfolio. This endogeneity of variances arises because of the linkages between sectors.

The variability, for example, of employment in the manufacturing sector (the $\left.\operatorname{VAR}\left[Z_{i}\right]\right)$ itself may depend on the variability of employment $\left(V A R\left[Z_{j}\right]\right)$ in the construction sector. The existence of linkages between different sectors underlies the use of various economic indicators to predict cyclical swings in economic activity. For example, information on the number of housing starts is a widely used indicator of economic activity in other sectors of the economy. The portfolio variance, because it fails to incorporate these endogenous changes in variances, provides an incomplete and distorted picture of the impact of structural change on regional economic stability. 
In order to formalize the notion that variances themselves are endogenous to the region's economic structure, consider the following model of a regional economy. ${ }^{1}$ The material balance equation for a region's output, by sector, can be expressed as:

$$
X=A X+F
$$

The $n \times 1$ vector $\mathbf{X}$ includes output by each of the region's $n-k$ industrial sectors and "output" (income received as payment for labor and capital supplied to the region's industrial sectors) by the region's households grouped into $k$ income classes. The nxn matrix A represents the region's technical input-output coefficients, which measure intersectoral linkages. The $\mathrm{nx} 1$ vector $\mathrm{AX}$ denotes the region's intermediate demands. The $\mathrm{nx} 1$ vector $\mathrm{F}$ includes the region's exogenous final demands for the industrial sectors' output such as sales to government, gross private domestic investment, and exports to other regions. The vector $F$ also includes expenditures for the industrial sectors' output that is purchased with households' income that is not directly related to the level of regional economic activity (e.g., transfer payments, remittances, and returns on assets held outside the region). ${ }^{2}$

Assuming that the usual input-output conditions are satisfied (e.g., the matrix $(I-A)$ is non-singular), the system of material balance equations can be solved as:

$$
X=(I-A)^{-1} F,
$$

where $(I-A)^{-1}$ is the Leontief inverse. ${ }^{3}$ The regional input-output model described in Equation (4) can be written in compact notation as:

$$
X=R F \text {. }
$$

In Equations (4) and (5), a region's economic performance (X) is expressed as a direct function of its economic structure (RF) using an input-output model. The region's demands, production technologies, and trade flows are included as part of the economic structure. Economic performance is measured as the level of sectoral output.

If $\mathbf{S}$ denotes the $\mathrm{nxn}$ diagonal matrix of employment: output coefficients (the number of employees from each of the $n-k$ industrial sectors required per dollar of output), and $\mathrm{Q}$ denotes the nxn diagonal matrix of income:output coefficients (the average wage plus capital income received by each employee in the $n-k$ industrial 
sectors per dollar of sectoral output), then:

$$
Z^{\text {employ }}=S X
$$

measures regional employment by sector, and

$$
Z^{\text {income }}=Q X
$$

measures regional income by sector. 4

From Equations (5), (6), and (7), it is clear that the variance of output (VAR $[X])$ and the variances of employment (VAR[SX]) and income (VAR[QX]) depend on the structure of the economy $(R F)$ and its variance VAR[RF]. Any changes in the technical input-output coefficients $(A)$ or the mix of exogenous final demands $(F)$ imply endogenous changes in each of the individual sector variances and covariances of $X, Z^{\text {employ }}$, and $Z^{\text {income }}$ because of the existence of intersectoral linkages.

A portfolio variance can be constructed for outcomes such as output, employment, or income. Altematively, the portfolio variance can be constructed for final demands $(F)$. If, however, the variances themselves are endogenous, as they are for $X, Z^{\text {employ }}$, and $Z^{\text {income }}$, they will change as the weights $\left(W_{i}\right.$ and $W_{j}$ in Equations [1] and [2]) change. In such a case, use of the portfolio variance to predict changes in aggregate region-wide economic stability following changes in the $W_{i}$ and $W_{j}$ is inappropriate.

If, however, the portfolio variance is constructed at the level of final demands (i.e., calculating $V A R[F]$ ), the problem of endogeneity can be avoided. $V A R[F]$ is clearly exogenously determined. The input-output model can then be used to generate endogenous variances and covariances of output (VAR[X]), employment (VAR[ $\left.\left.Z^{\text {employ }}\right]\right)$, and/or income (VAR[ $\left.\left.Z^{\text {income }}\right]\right)$ by sector. That is, if it can be assumed that the instability in employment and income is primarily generated by fluctuations in exogenous final demands ( $R$ is assumed to fluctuate only slightly), the variance of regional output can be approximated as:

$$
V A R[X]=R \operatorname{VAR}[F] R^{T}
$$

where $V A R[F]$ is the variance-covariance matrix of final demands, and the superscript $T$ denotes a matrix transpose. The above model suggests a means of applying the portfolio variance so that the problem of variance and covariance endogeneity is eliminated. 5 
Substituting VAR[F] for VAR[Z] in Equations (1) and (2), and using Equations (6) and (8), the exogenously generated VAR[F] can then be used to create a portfolio variance PVAR[Z] that more accurately reflects regional economic stability. Such a substitution gives:

$$
\operatorname{PVAR}\left[Z^{\text {employ }}\right]=\sum_{i=1}^{n} \sum_{j=1}^{n}(S R) W_{i} W_{j} V A R\left[F_{i j}\right]\left(R^{T} S^{T}\right)
$$

for an employment portfolio variance. The income portfolio variance could be calculated in a similar manner using Equation (7) instead of (6). However, more data are required to generate the "improved" portfolio variance measure described in Equation (9) than the commonly used portfolio variance measure in Equations (1) and (2). These additional data requirements can limit use of the improved measure of portfolio variance and explain, in part, the popularity of the commonly used measure. $^{6}$

Two widely used strategies for economic diversification could be modelled using Equation (9). A diversification strategy based on changing the mix of the region's exports could be modelled by varying the shares of different types of exogenous final demands (i.e., changes in $W_{i}$ and $W_{j}$ ). A diversification strategy based on import substitution could be modelled by changing the technical inputoutput coefficients (i.e., changes in the $A$, and thereby changes in $R$ ).

Any time the variance-covariance matrix used in computing the portfolio variance is calculated at the level of final outcomes (output, income, or employment by sector), changes in the weights (the $W_{i}$ and $W_{j}$ in Equation [2]) will lead to a change in the computed PVAR[Z], but the change will not include the effects of the endogenous changes as captured using Equation (9). Because of this omission, the predicted change in PVAR[Z], when calculated using final outcomes, will be inaccurate. Thus, this method of calculating the portfolio variance will provide an imperfect measure of how a change in structure will affect overall regional economic stability, since the variances in the existing portfolio will depend on which sector's level of economic activity increases or decreases, and how such a change in activity is transmitted through the economy via intersectoral linkages. Clearly the strength of these linkages, and thus the extent of the problem of ignoring the endogeneity of variances and covariances, will vary among regions.

\section{AGGREGATE REGION-WIDE STABILITY AS AN OBJECTIVE}

Portfolio theory was first developed for applications to financial assets. Using the mean and variance of returns, the Markowitz (1959) portfolio method 
determines the set of mean-variance (E-V) efficient portfolios. The E-V trade-offs that underlie this theory are generally not considered when using a portfolio variance approach to regional economic stability. By using the portfolio variance alone as a guide in the ranking of alternative divensification strategies, it is implicitly assumed that decisions are based on the objective function of a risk-averse policymaker whose sole goal is to minimize region-wide instability. If, in addition to economic stability, growth and distributional impacts are important to policymakers, then use of the portfolio variance is valid only when growth rates and distributional impacts are either satisfactory or positively correlated to economic stability. While these assumptions may be valid for some regions and some circumstances, they are not universally valid, especially for economically distressed regions.

Some recent studies have proposed portfolio-based models of diversification that incorporate growth-stability (E-V) trade-offs (Board and Sutcliffe 1991; Bolton 1989; Gilchrist and St. Louis 1991). However, to date, the issue of distributional impacts has not received sufficient attention or appropriate treatment.

\section{Who Benefits from Stability?}

When using a portfolio variance to assess economic stability, the policymaker may ask: "Stability for whom?" Overall region-wide stability may be enhanced by a specific diversification strategy, but the region is composed of individuals and firms grouped by households, occupations, sectors, etc., and outcomes for some of these groups may be more or less stable following the diversification program.

Some studies that use the portfolio variance approach to rank altemative diversification strategies compare each subgroup's (e.g., each sector's) contribution to regional instability by analyzing the share weighted rows (columns) of the variance-covariance matrix VAR[Z] (e.g., Gruben and Phillips 1988; Kurre and Weller 1989; Wundt 1992). For example, the ith sector's contribution to regionwide employment instability can be measured as:

$$
\operatorname{PVAR}\left[Z_{i}^{\text {employ }}\right]=W_{i}^{2} \operatorname{VAR}\left[Z_{i}^{\text {employ }}\right]+\sum_{j=1, j \neq i}^{n} W_{i} W_{j} \operatorname{COV}\left[Z_{i}^{\text {employ }}, Z_{j}^{\text {employ }}\right] \text {. }
$$

These studies generally focus attention on the impact of intergroup fluctuations on region-wide economic instability and not on the individual group's instability. In fact, these studies have found that the covariances typically account for a significant proportion of the total portfolio variance for a region. However, they tend to ignore individual group's instability, $\operatorname{VAR}\left[Z_{i}\right]$, by focussing on the contribution of each group to aggregate region-wide instability. ${ }^{7}$ 
The portfolio variance, by construction, is based on the assumption that offsetting fluctuations in income and employment of different groups can stabilize region-wide income and employment. Although these offsetting fluctuations may benefit the region as a whole, individuals and firms are affected most by variations in employment and income for their own respective groups. Because of this divergence between aggregate (i.e., region-wide) versus individual stability, the portfolio variance presents a misleading picture of the welfare impacts of policy alternatives.

The limitation of using PVAR[Z] to rank altematives is made apparent by the following example. Take a region with two highly variable sectors whose fluctuations are perfectly and negatively correlated. A second region composed of two mildly variable sectors with perfectly and negatively correlated fluctuations will yield the same PVAR[Z], ceterus paribus, as the first. The portfolio variance, because it collapses all information on variability by sector into a single measure, ranks these two altematives equally. The fluctuations in these two regions are likely to have very different equity impacts. If, for example, sectoral income was used to construct the portfolio variance and if risk aversion is assumed, then individual workers in the first region would be worse off (because their incomes would be more variable) than workers in the second region. Unemployment insurance is one such institutional arrangement that exists to redistribute income from winners to losers.

A perhaps more egregious example of poor information provided by PVAR[Z] is the case where one region has mildly fluctuating sectors with a perfect positive covariation, and a second region has highly variable sectors with strong negative covariations. The second region would generally be ranked more stable by the PVAR[Z] measure.

These two examples demonstrate that when economic instability is evaluated at a region-wide level of aggregation, it is implicitly assumed that overall regionwide stability is desirable, and the distribution among groups is masked. The portfolio variance itself provides little information about who wins and loses in the stabilization process. ${ }^{8}$ Clearly, this is not a problem when applying portfolio models to financial assets held by individuals. In the case of financial assets, the portfolio variance (and any E-V trade-offs) are explicitly modelled from the individual's perspective.

When decisions are made based on limited information about distributional impacts, a possible decision rule is the "weak Pareto rule," whereby social state B is deemed an improvement over social state $\mathbf{A}$ if, in a change from $\mathbf{A}$ to $\mathbf{B}$, winners can hypothetically compensate losers. Using this rule, state B may be preferred to $A$ even if the rich benefit and the poor become more disadvantaged. In the case of instability in employment, those individuals who can move from 
one sector to another benefit from the aggregate region-wide economic stability created by sectors whose fluctuations are negatively correlated with their own. Such mobile labor benefits when policymakers bring in a counter-cyclical economic activity. For the vast majority of residents, this mobility is impossible, and their welfare will be unchanged by the introduction of a counter-cyclical stabilizing sector. 9

The weak Pareto rule may be the social ordering criterion used by the political process in some regions, but it is not a universally accepted decision rule. In cases where the political process requires more information about winners and losers, the analyst must be prepared to examine and adjust the level of aggregation accordingly. ${ }^{10}$

In any case, even if individual sectoral stability is examined by using Equation (10), the picture will be distorted unless the procedure described earlier is used to endogenize the variances. Without this procedure, the forward and backward linkages in an economy ensure that many of the component variances are affected by a change in economic structure. For example, sectors whose own stability is enhanced by the stability of the rest of the economy, such as service sectors, will not appear as winners, since the portfolio variance approach treats variances as exogenous.

\section{Resource Mobility}

In much of the literature that uses the portfolio variance to measure regionwide stability (and diversity), it is assumed that labor and capital move between sectors within a region or from region to region when different sectors experience counter-cyclical fluctuations. If labor and capital are not mobile, then economic stability requires excess "surplus" labor and capital that can adjust to economic fluctuations. Consider, in particular, the case of labor.

In order for labor to be mobile between sectoral (or occupational) subgroups within a region, it must be relatively homogeneous. ${ }^{11}$ If it is not assumed that labor is mobile across sectors, then it must be assumed that an unconstrained supply of labor (chronic or frictional unemployment) exists. That is, if labor is not mobile, although aggregate region-wide employment may be stable, there might be continued instability in some sectors or occupations.

The assumption of homogeneous labor is clearly inappropriate, given observed intra- and intersectoral labor heterogeneity. In reality, there can be a great deal of heterogeneity of occupations within and among sectors. ${ }^{12}$ This heterogeneity can inhibit the movement of labor between subgroups and can make labor from some subgroups less substitutable for labor in other subgroups. Imperfect substitutability of labor implies the need for more disaggregated measures of 
regional economic instability (and diversity) in order to measure the distributional impacts of altemative diversification strategies. Since neither the assumption of perfect mobility nor the assumption of abundant labor supplies (especially of suitably skilled workers) is acceptable, the employment and income impacts of counter-cyclical stabilizing fluctuations on disaggregated groups should be considered when using the portfolio variance. Assumptions about the interregional mobility of labor also need to be examined.

Grouping individuals by occupation, rather than by sector, can provide important information for planning purposes. For regions contemplating industrial targeting and recruitment, there are practical advantages to conducting an analysis where employment and income outcomes are measured by occupation group. A region's human resource base should be assessed to determine how labor can be most efficiently employed. The occupation mix can also be a constraint. In many economically disadvantaged regions, a major constraint to diversification efforts is the low-skill level and specialized occupation mix of the labor force.

\section{CONCLUDING REMARKS}

The portfolio variance has gained popularity as a tool to evaluate altemative strategies that promote regional economic stability. The portfolio variance can provide some insights for regional economic analysis. As it is commonly applied, however, the portfolio variance has several problems that limit its appropriateness. There are several implicit assumptions about the relationship between structural change and stability and about the emphasis on aggregate region-wide stability that should be recognized when using the portfolio variance approach to predict the impact of alternative diversification strategies on a region's economic stability.

An analysis of the impacts on groups within the region is critical when evaluating and ranking diversification strategies aimed at enhancing economic stability. Use of the portfolio variance is based on the assumption that offsetting fluctuations of employment and income by individuals or firms (grouped by sector, occupation, household, etc.) will stabilize aggregate region-wide employment and income. Without information about the impacts of such offsetting fluctuations on these groups, the effect of a given economic strategy on overall social welfare cannot be determined.

When using a portfolio variance approach to economic diversification, the implied policy goal is region-wide aggregate stability. This may be an acceptable goal for policymakers who are interested in stabilizing public revenue flows and expenditures. Even then, aggregate stability may not guarantee stable revenue 
flows if income groups with different propensities to consume, or different tax rates, are affected differently by cyclical fluctuations. To determine whether a particular change benefits revenue or expenditure stability, a suitably disaggregated approach is needed.

Most importantly, this paper argues that although the portolio variance does provide an accurate measure of overall instability at a given point in time (i.e., for a given economic structure), it does not necessarily provide a method to identify stability-promoting industries (i.e., for a changing economic structure). Because it treats variances and covariances as exogenous, the portfolio variance as it is commonly computed provides a distorted picture of the changes in both individual sector and aggregate instability that would result from a change in economic structure. This deficiency has clear implications for the use of the portfolio variance approach. First, it limits the ability to identify winners and losers much in the same way that the aggregation problem does. Second, it suggests that the variance-covariance matrix that is central to the portfolio variance approach should be constructed in such a way that the exogeneity assumption is reasonably acceptable.

Without recognizing these limitations to the application of portfolio variance techniques to regional economic diversification, an incomplete and distorted picture of the impact of structural change on aggregate stability and on the stability of individuals emerges. Without disaggregated information on outcomes, it becomes impossible to rank or even identify individual winners and losers. The issue of distribution is serious and can only be remedied by a more disaggregated approach. The problem of endogeneity of variances is equally serious, but the approach outlined in this paper can be used to make portfolio variance techniques acceptable for analyses of aggregate stability. As pointed out, the data requirements for this approach are more demanding than for the commonly used portfolio variance. This might discourage some practitioners from using the alternative approach.

\section{ENDNOTES}

1. The following model of a regional economy is based on an input-output framework. See Miller and Blair (1985, chaps. 2-3) for a good background into input-output analysis. In particular, see pages 25-27 for a concise description of an input-output model that is closed with respect to households (i.e., households are considered a sector in a manner similar to industrial sectors).

2. Transfer payments include Social Security, unemployment assistance, and other public assistance. Some of these transfer payments might be directly related 
to the level of economic activity in the region. Unemployment benefits, for example, might be negatively correlated to fluctuations in regional economic activity. The input-output model can be extended to reflect such transfer payments that are endogenous to the level of economic activity (Bemat 1993).

3. The input-output model of a regional economy developed in Equations (3) and (4) is subject to all the strengths and weaknesses commonly attributed to input-output models. For example, the construction of material balance equations from regional economic accounts is based on the assumption that each sector uses fixed proportion production technologies to produce homogeneous outputs. The input-output model assumes that there are constant returns to scale, no capacity constraints, fixed prices, no substitution among inputs, and frictionless adjustments.

4. Alternatively, if we denote $S$ as the sxn matrix of employee-by-occupation:output coefficients (the number of employees by occupation class required per dollar of output), and $Q$ as the sxn matrix of income-by-occupation:output coefficients (average income received by each employee in an occupation class), the regional employment and income by occupation class could be measured. In many cases, the availability of data (e.g., Bureau of Census and Bureau of Labor Statistics data) dictates an aggregation of regional income and employment by sector rather than by occupation group.

5. The use of Equation (8) is based on the assumption that the instability of a region's output, employment, and income is primarily generated by fluctuations in exogenous final demands. This assumption underlies business cycle theory. If this assumption is not valid, then Equation (8) would need to be extended to include the effects of the variance of $R$ and covariance between $R$ and F. Such an extension is straightforward. The extent that fluctuations in exogenous final demands actually generate regional fluctuations in employment and income is a subject of ongoing research (Jackson and West 1989).

6. The input-output framework presented in Equations (3) to (5) is a special case of a Social Accounting Matrix, or SAM. The SAM-based model in this paper requires data from input-output accounts and data on household income. See Miller and Blair (1985, chaps. 5 and 8), Rose et al. (1988, chaps. 4 and 6), and Bernat and Johnson (1991) for information on data requirements and sources. Widely used input-output models such as IMPLAN and REMI are SAM-based models with extensive databases (see Crihfield and Campbell 1991; 1992 for descriptions of these models). The data requirements are magnified by the need for time series data to construct the variance-covariance matrix of exogenous final demands. Since time series data on exogenous final demands are, in general, hard to obtain, it might be necessary to use other data (e.g., national-level data) to approximate the sectoral fluctuations in a region's exogenous final demands. 
7. It should be pointed out that the level of disaggregation referred to in these studies is the number of groups (i.e., the value of $n$ in Equation [10]) used to calculate the aggregate region-wide portfolio variance.

8. One possible winner from increased region-wide stability is the unit of government whose revenues and expenditures vary with the level of region-wide economic activity (e.g., revenues generated through sales or income taxes, and expenditures such as unemployment benefits and welfare payments). Possible losers in the stabilization process are those groups who have an interest in the opportunities foregone by choosing to stabilize the region's economy.

9. It should not be inferred from this discussion that an individual cannot benefit from a more stable region-wide economy unless that individual experiences more stable employment or income. Surely some unemployed individuals can benefit (to some extent) from the employment of others in the region. The authors' focus here on individual outcomes is not intended to overlook the positive externalities associated with greater aggregate region-wide stability. Indeed, a balanced perspective between private and public benefits and costs resulting from strategies designed to increase region-wide economic stability is required.

10. Gilchrist and St. Louis (1991) present a portfolio-based model of regional economic diversification that measures economic impacts in terms of the growth and stability of sectoral income. In this case, the decision rule is the "strong Pareto rule"; that is, an unambiguous improvement in social welfare occurs only if some sectors experience improved growth and greater stability while no sectors experience a deterioration in growth or stability. An unambiguous deterioration in social welfare can be determined in a like manner. All other outcomes are ambiguous (i.e., a mix of winners and losers), and the political process must rank them.

11. For example, Gilchrist and St. Louis (1991) explicitly assume that labor is homogeneous and mobile between sectors. In their simulation of alternative diversification strategies, they allow the labor force to be reallocated between sectors. In one application of the model, they assume that labor from the agricultural sector can move freely to nonagricultural sectors.

12. See, for example, Reich (1983, chap. 10) and Drucker (1989, 180-186) for discussions about labor mobility or immobility among and within sectors.

\section{REFERENCES}

Bemat, A. "Impacts of Transfer Payments." In Microcomputer-Based Input-Output Modeling: Applications to Economic Development, edited by D. Otto and T. G. Johnson. Boulder, Colo.: Westview Press, 1993. 
Bernat, A., and T. G. Johnson. "Distributional Effects of Household Linkages." American Journal of Agricultural Economics 73 (1991): 326-333.

Board, J., and C. Sutcliffe. "Risk and Income Tradeoffs in Regional Policy: A Portfolio Theoretic Approach." Journal of Regional Science 31 (1991): 191210.

Bolton, R. "Strategic Regional Planning, A Portfolio Model of Regional Diversification, and Regional Benefit-Cost Analysis." In Regional Development Processes and Policies, edited by W. H. Berensten, D. R. Danta, and E. Daroczi. Budapest, Hungary: Centre for Regional Studies, Hungarian Academy of Sciences, 1989.

Conroy, M. E. "Altemative Strategies for Regional Industrial Diversification." Journal of Regional Science 14 (1974): 31-46.

"The Concept and Measurement of Regional Industrial Diversification." Southern Economic Journal 41 (1975): 492-505.

Crihfield, J. B., and H. S. Campbell. "Evaluating Alternative Regional Planning Models." Growth and Change 22 (1991): 1-16.

. "Evaluating Altemative Regional Planning Models: Reply." Growth and Change 23 (1992): 521-530.

Drucker, P. F. The New Realities. New York: Harper and Row, 1989.

Gilchrist, D. A., and L. V. St. Louis. "Directions for Diversification With an Application to Saskatchewan." Journal of Regional Science 31 (1991): 273-289.

Gruben, W. C., and K. R. Phillips. "Diversifying Texas: Recent History and Prospects." Economic Review (Federal Reserve Bank of Dallas)(July 1988): 1-12.

Jackson, R. W., and G. R. West. "Perspectives on Probabilistic Input-Output Analysis." In Frontiers of Input-Output Analysis, edited by R. E. Miller, K. R. Polenske, and A. Z. Rose. New York: Oxford University Press, 1989.

Kort, J. R. "A Perspective on the Economic Diversity/Instability Literature: Are We Really Providing Directions and Policy Prescriptions?" Paper presented at the North American Meetings of the Regional Science Association International, New Orleans, Louisiana, November 7-10, 1991.

Kurre, J. A., and B. R. Weller. "Regional Cyclical Instability: An Empirical Examination of Wage, Hours and Employment Adjustments, and an Application of the Portfolio Variance Technique." Regional Studies 23 (1989): 315-329.

Markowitz, H. M. Portfolio Selection. New York: Wiley Press, 1959.

Miller, R. E., and P. D. Blair. Input-Output Analysis: Foundations and Extensions. Englewood Cliffs, N.J.: Prentice-Hall, 1985.

Reich, R. B. The Next American Frontier. New York: Times Books, 1983. 
Rose, A., B. Stevens, and G. Davis. Natural Resource Policy and Income Distribution. Baltimore: The Johns Hopkins Press, 1988.

Schoening, N. C., and L. E. Sweeney. "Applying an Industrial Diversification Decision Model to Small Regions." Review of Regional Studies 19 (1989): 14-17.

"Proactive Industrial Development Strategies and Portfolio Analysis." Review of Regional Studies 22 (1992): 227-238.

Sherwood-Call, C. "Assessing Regional Economic Stability: A Portfolio Approach." Economic Review (Federal Reserve Bank of San Francisco) (Winter 1990): $17-26$.

Wundt, B. D. "Reevaluating Altemative Measures of Industrial Diversity as Indicators of Regional Cyclical Variations." Review of Regional Studies 22 (1992): 59-73. 